\title{
INHERITANCE OF SELF-INCOMPATIBILITY IN PLANTAGO LANCEOLATA
}

\author{
M. D. ROSS \\ Botany School, Oxford University, and Department of Biology, Dalhousie University, \\ Halifax, Nova Scotia* \\ Received 10.iv.72
}

\section{SUMMARY}

\begin{abstract}
Plantago lanceolata is self-incompatible and gynodioecious, and a knowledge of the genetics of these two systems may help in understanding why male sterility is present when self-incompatibility alone is sufficient to ensure crossing. This paper reports on the inheritance of self-incompatibility. Self-incompatibility is inherited through one gene with at least four alleles. Matings are incompatible if the pollen carries either of the two alleles present in the style. Control of the pollen incompatibility reaction is gametophytic, and there is individual action of the alleles present in the style.
\end{abstract}

\section{INTRODUCTION}

SELF-INCOMPATIBILITY is one of the most important of the several outbreeding mechanisms known in the flowering plants, and it has been the subject of many genetic studies. Another breeding system of interest is gynodioecy, a situation where separate male-sterile (i.e. female) and hermaphrodite plants are found in a population. Gynodioecy has been interpreted as an outbreeding mechanism (Mather, 1940), but is less common and has been less studied than self-incompatibility. Plantago lanceolata and a few other species are both self-incompatible and gynodioecious, a fact which has led to the question of what is the function of the male-sterile plants in these species. Since not only the male steriles, but also the hermaphrodites must be outcrossed, the male sterile may appear to be superfluous with regard to outbreeding (Baker, 1963).

In order to understand the relationship between gynodioecy and selfincompatibility in species with both breeding systems, it is desirable to study the genetics of these species. A previous study of gynodioecy in Plantago lanceolata has shown that two genes, together with some unknown additional factor, govern the inheritance of male sterility (Ross, 1969). The present paper continues the study of the breeding systems of this species by describing the mode of inheritance of self-incompatibility.

\section{Materials and MEthods}

The first series of crosses was made with plants obtained from a natural population from Oxford, and with their offspring. Later generations of this line were difficult to maintain and score with respect to incompatibility; these plants were replaced for a second series of crosses with plants that had previously been used to study male sterility. Because of the difference in

* Present address: Grasslands Division, D.S.I.R., Palmerston North, New Zealand. 
origin, allele designations in the two series of crosses do not necessarily correspond.

Plants were kept in a greenhouse with natural lighting, supplemented when necessary with light from high-pressure mercury-vapour lamps (18-hour daylength). Inflorescences were usually isolated in translucent paper bags, but occasionally plants were isolated by distance. Many crosses were made at least twice, usually with concordant results. The species is protogynous, and flowers mature from the base of the inflorescence upwards, thus allowing artificial crossing without emasculation. Natural self-pollination followed artificial pollination by a period of about 8 to more than 60 hours. Assessment of incompatibility reaction by seed set sometimes gave anomalous results, but compatible matings could usually be distinguished quite readily by inspection of the style, which became brown and withered within 48 hours, and sometimes within 24 hours, of a compatible pollination. Styles after incompatible pollinations usually remained fresh and white for most of their length for 48 hours or longer, but it proved best to score matings after about 48 hours. The assessment of incompatibility reaction according to the appearance of the style is similar to its assessment by stylar colour reaction in Iberis amara (Bateman, 1954). Results assessed by seed set confirmed those by style inspection in 175 out of 190 matings where the comparison was made (92.1 per cent.). Ambiguous results appeared to occur mostly after incompatible matings, and are assumed to result from weak or variable incompatibility reactions, such as are commonly found among self-incompatible plants (East and Park, 1917).

\section{REsULts}

Series 1

Two self-incompatible plants were crossed, and 13 offspring of this cross were reciprocally intercrossed and backcrossed to the surviving (female) parent. With one anomalous result, the offspring fell into four intra-sterile inter-fertile classes (table 1), and all offspring were reciprocally compatible with their female parent. The presence of four classes suggests that the incompatibility reaction is governed by one rather than by two genes. The results suggest also that there are four incompatibility alleles, and that pollen grains having either of the two alleles present in the style are incompatible. The general absence of reciprocal differences in incompatibility, the absence of cross-incompatibility among classes and the absence of incompatibility with the female parent tend to rule out sporophytic (diploid) control of the pollen incompatibility reaction, since the presence of these features is associated with such sporophytic control (Lewis, 1954). In contrast, the absence of these features is consistent with gametophytic control of the pollen incompatibility reaction, and with individual action of each allele in the style, as found in Nicotiana hybrids by East and Mangelsdorf (1925), and by many authors since.

Preliminary results with five families derived from compatible matings listed in table 1 suggested that each family might be segregating into two classes. Results of more intensive studies on four such families are given in tables 2 and 3 . Table 2 gives the results derived from intercrossing and selfing the progeny from crosses between the first two classes of table 1; the progeny have been arranged into two classes. This two-class segregation is 
TABLE 1

Results of reciprocally crossing a family of 13 plants among themselves and with one parent

Cl. I

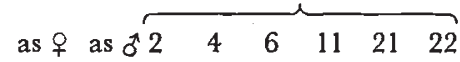

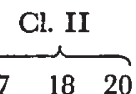

$\begin{array}{lll}7 & 18 \quad 20\end{array}$

$++t$

$++t$

$++t$

$++t$

$+t+$
Cl. III

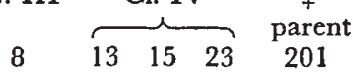

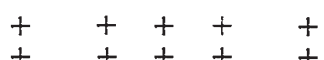

Cl. II $\left\{\begin{array}{l}7 \\ 18 \\ 20\end{array}\right.$

$\begin{array}{llllll}+ & + & + & + & + & + \\ + & + & + & + & + & + \\ + & + & + & + & + & +\end{array}$

$\begin{array}{lll}- & - \\ \pm & -\end{array}$

$\begin{array}{lllll}+ & + & + & + & + \\ + & + & + & + & + \\ + & + & + & + & +\end{array}$

Cl. III 8

Cl. IV $\left\{\begin{array}{l}13 \\ 15 \\ 23\end{array}\right.$

$++++++$

$+++$

$-$

$++++$

parent 201

+++
$+\quad+\quad+$
$+\quad+$

+
+
+

$-$

$\begin{array}{lll}- & -* & + \\ -s & - & + \\ - & +\end{array}$

$+=$ Compatible $;{ }^{*}=$ Partly compatible by style inspection, but set seed; - = Incompatible; $-^{*}=$ Weakly incompatible $\pm=$ Both compatible and incompatible results were recorded with different inflorescences; $-s=$ Incompatible, as judged by failure to set seed. A 16-class two-locus segregation is excluded here, since the probability of obtaining four or less out of 16 equally frequent classes is $<0.05$ after the sample size reaches 8 (Lewontin and Prout, 1956). However, 12-class two-locus segregations have been observed in crosses between apparently unrelated plants; for such a 12-class segregation $\mathrm{P}$ for four or less classes is $<0.05$ after the sample size reaches 9 .

TABLE 2

Results of reciprocally intercrossing five offspring of the cross Class $I \times$ Class $I I$ of table 1 . The plants were derived from the cross $11 \times 18(11-2,11-11,11-34,11-42$ and 11-43), and from the cross $11 \times 7$ (11-102)

Gl. I

as $\begin{array}{ccc}\overbrace{11-2}^{11-34} & 11-42 \\ \pm & - & - \\ - & - & - \\ & & - \\ & + & + \\ & + & + \\ & + & +\end{array}$

Cl. II

$\begin{array}{ccc}\text { 11-11 } & 11-43 & 11-102 \\ + & + & + \\ + & + & + \\ + & \pm & + \\ - & - & - \\ - & - & - \\ - & - & -\end{array}$

Four self-incompatible plants from the cross $11 \times 7$ showed varying or anomalous incompatibility reactions, and are omitted from the table. This variant behaviour appears to result from weak incompatibility reactions in this family, and from technical difficulties experienced in later Series 1 crosses.

$+=$ Compatible; $-=$ Incompatible $\pm=$ Both compatible and incompatible results were recorded with different inflorescences.

consistent with the gametophytic incompatibility system suggested by the results of the first generation, and would be expected if the parent plants had a common incompatibility allele. 
Table 3 gives the result of intercrossing the progeny derived from the backcross of class I of table 1 to its female parent, and from the reciprocal backcross. Despite the occurrence of some unclear incompatibility reactions, the progeny fell into three well-defined incompatibility groups. Each family contained only two such groups, of which one only (class I) was identical to one incompatibility group from the other family, to give a total of three groups. Such a result would be expected from intercrossing the progeny of a common-allele cross and of its reciprocal under a gametophytic incompatibility system. Thus if we assign the genotype $S_{1.2}$ to the original parent plant 201, and the genotype $S_{3.4}$ to the other original parent, and if we let plant 11 of table 1 (which is one of their offspring) be $S_{1.3}$, then the cross $201 \times 11$ and reciprocal can be represented as under: $S_{1.2} \times S_{1.3} \rightarrow S_{1.3} S_{2.3}$, and $S_{1.3} \times S_{1.2} \rightarrow S_{1.2} S_{2.3}$, where $S_{2.3}$ is the class common to both families.

TABLE 3

Results of reciprocally intercrossing seven offspring from the cross parent $\times$ Class $I$ of table 1 , and reciprocal (plants $201 \times 11$, and reciprocal)

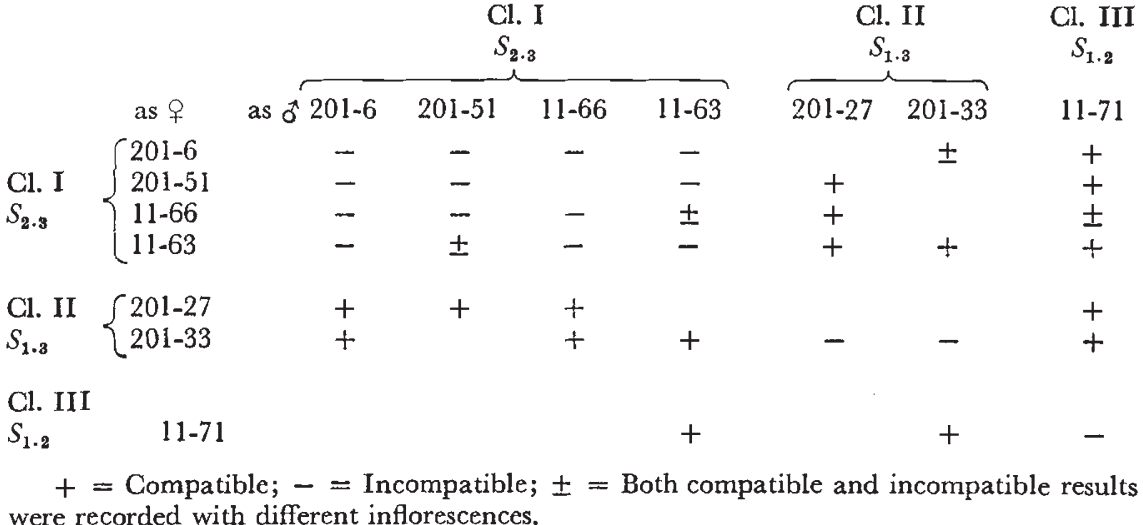

Series 2

In order to distinguish gametophytic from sporophytic pollen control with more certainty, it is desirable to backcross a progeny with both parents. This proved possible during a second series of crosses using three plants and their offspring derived from a study of male sterility. The three plants were the progeny of a backcross (MS1-1 $\times$ H3 of Ross, 1969), and thus were expected to have at least one common incompatibility allele. Plant 205 was male sterile, while 204 and 203 were hermaphrodite. Plants 205 and 204 were cross-incompatible, and both plants were compatible with 203. Tables 4 and 5 each reveal two classes of offspring, as expected with commonallele crosses. Furthermore, these tables reveal a pattern of behaviour characteristic of gametophytic incompatibility in that both classes of progeny are compatible with the female parent, whereas only one class of progeny is compatible, while the other is incompatible, with the male parent.

In table 6 only one class of progeny appears, namely that incompatible with the male parent. An attempt was made to find a second class by crossing more of this progeny to the male parent, to look for compatible plants. Two of these extra plants (203-14 and 203-17) were incompatible, and two (203-10 
TABLE 4

Results of reciprocally intercrossing and backcrossing to both parents seven progeny of a common-allele cross $(204 \times 203)$

\begin{tabular}{|c|c|c|c|c|}
\hline $\begin{array}{l}\text { PI } \\
S_{1.2}\end{array}$ & $\underset{S_{1.3}}{\text { PII Gl. I }}$ & & & $\begin{array}{l}\text { Gl. I } \\
S_{2.8}\end{array}$ \\
\hline$\sigma^{2} 20$ & $203 \quad 204-7$ & 204-1 & 204-2 & 204- \\
\hline
\end{tabular}

PI $S_{1.2} 204$
PII $\left\{\begin{array}{llllllllll}203 & & + & + & + & \pm & & + & + & + \\ 204-7 & + & & -* & + & + & + & + & + & +\end{array}\right.$
$S_{1.3}$

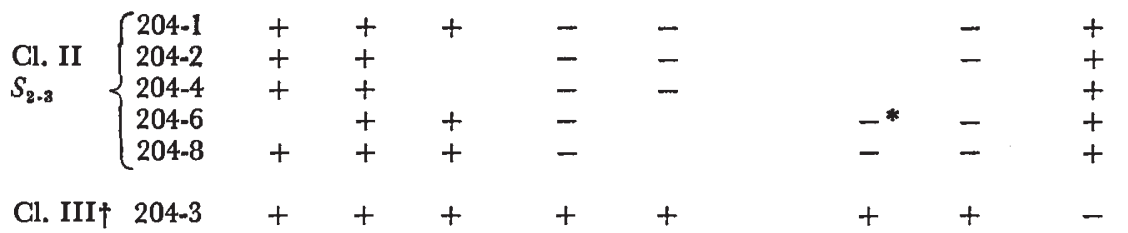

One weakly incompatible plant which gave variable reactions on crossing was omitted. $+=$ Compatible; - = Incompatible $\pm=$ Both compatible and incompatible results were recorded with different inflorescences; - * = Weakly incompatible.

$\dagger$ The unexpected occurrence of a third class is perhaps best understood as the result of an accidental pollination; however the possibility of the generation a new incompatibility specificity by recombination after inbreeding cannot be ruled out (Denward, 1963; Pandey, 1970).

TABLE 5

Results of reciprocally intercrossing and backcrossing to both parents six progeny of a common-allele cross $(205 \times 203)$

\begin{tabular}{|c|c|c|c|c|c|c|c|c|c|}
\hline & & $\begin{array}{l}\text { PI } \\
S_{1.2}\end{array}$ & & PII & I. I & & & $\underset{S_{2.8}}{\text { Cl. II }}$ & \\
\hline & as $q$ & as $\sigma^{7} 204 \dagger$ & 203 & 205-2 & $205-4$ & 205.6 & 205-1 & $205-3$ & $205-5$ \\
\hline PI $S_{1.2}$ & $204 \uparrow$ & - & + & & + & + & + & + & + \\
\hline & $\int 203$ & + & & $-*$ & - & - & + & + & + \\
\hline PII & $\{205-2$ & & - & - & - & - & & + & + \\
\hline Cl. I $S_{1.3}$ & $205-4$ & + & - & - & - & - & + & + & + \\
\hline & (205-6 & + & - & - & - & - & + & + & + \\
\hline & 205-1 & + & + & + & + & + & - & - & - \\
\hline Cl. II $S_{2 \cdot 8}$ & $\{205-3$ & + & + & & + & + & - & & - \\
\hline & 205-5 & + & + & + & + & + & - & - & - \\
\hline
\end{tabular}

$\uparrow$ Because of the unavailability of plant 205 , the genetically equivalent plant 204 was substituted.

$+=$ Compatible; - = Incompatible; $-^{*}=$ Weakly incompatible.

and 203-12) were compatible with the male parent, thus revealing the second class.

Finally, one plant was chosen to represent each class of each of the three progenies in the second series of crosses, and these six testers were intercrossed to reveal any cross-incompatibility. The results are given in table 7 , and show the same pattern of three classes of progeny expected on reciprocally crossing plants having a common $S$ allele. 
TABLE 6

Results of reciprocally intercrossing and backcrossing to both parents seven progeny of a common allele cross $(203 \times 204)$

\begin{tabular}{|c|c|c|c|c|c|c|c|c|c|c|}
\hline & & $\begin{array}{l}\text { PI } \\
S_{1.3}\end{array}$ & PII & & & & & & & \\
\hline & as $q$ a & 203 & 204 & 203-1 & 203-2 & 203-3 & $203-4$ & $203-6$ & 203-8 & $203-9$ \\
\hline PI $S_{1.3}$ & 203 & & + & + & + & + & + & + & + & + \\
\hline PII & 204 & + & - & - & - & - & - & - & - & - \\
\hline & 203-1 & + & - & - & - & - & - & - & & - \\
\hline & $203-2$ & + & - & - & - & - & - & - & - & \\
\hline & 203-3 & + & - & & & - & & & & \\
\hline Cl. I $S_{1.2}$ & $203-4$ & + & - & - & - & & - & - & - & \\
\hline & $203-6$ & + & - & - & - & - & - & \pm & $-*$ & - \\
\hline & $203-8$ & + & - & - & - & $-*$ & - & $=$ & - & - \\
\hline & $203-9$ & + & - & & - & - & & & & - \\
\hline
\end{tabular}

Results of crossing one self-compatible and one nearly self-compatible plant are omitted. $+=$ Compatible; $-=$ Incompatible; $\pm=$ Both compatible and incompatible results were recorded with different inflorescences; ${ }^{*}=$ Weakly incompatible. A second class, compatible with the male parent, was discovered by making further crosses (see text). The overall segregation was $9 \mathrm{Cl}$. I: $2 \mathrm{Cl}$. II (P for $1: 1<0 \cdot 05$ ).

\section{TABLE 7}

Results of intercrossing and backcrossing plants representing the various classes recorded in tables 4, 5 and 6

\begin{tabular}{|c|c|c|c|c|c|c|c|c|c|}
\hline & & & $\begin{array}{c}\text { Cl. I } \\
S_{2 \cdot 3}\end{array}$ & & & $\begin{array}{c}\text { Cl. II } \\
S_{1.3}\end{array}$ & & & \\
\hline & as $q$ as & $03-10$ & 204-1 & $205-3$ & 203 & $204-7$ & $205-4$ & 203-2 & 204 \\
\hline Cl. I $S_{2 \cdot 3}$ & $\left\{\begin{array}{l}203-10 \\
204-1 \\
205-3\end{array}\right.$ & - & - & - & + & $\begin{array}{l}+ \\
+\end{array}$ & $\begin{array}{l}+ \\
+\end{array}$ & $\begin{array}{l}+ \\
+\end{array}$ & $\begin{array}{l}+ \\
+ \\
+\end{array}$ \\
\hline Cl. II $S_{1,3}$ & $\left\{\begin{array}{l}203 \\
204-7 \\
205-4\end{array}\right.$ & + & $\begin{array}{l}+ \\
+ \\
+\end{array}$ & $\begin{array}{l}+ \\
+ \\
+\end{array}$ & $\overline{-}$ & $\begin{array}{l}-* \\
-* \\
-\end{array}$ & $\begin{array}{l}- \\
- \\
-\end{array}$ & $\begin{array}{l}+ \\
+ \\
+\end{array}$ & $\begin{array}{l}+ \\
+ \\
+\end{array}$ \\
\hline Cl. III $S_{1.2}$ & $\left\{\begin{array}{l}203-2 \\
204\end{array}\right.$ & $\begin{array}{l}+ \\
+\end{array}$ & $\begin{array}{l}+ \\
+\end{array}$ & $\begin{array}{l}+ \\
+\end{array}$ & $\begin{array}{l}+ \\
+\end{array}$ & $\begin{array}{l}+ \\
+\end{array}$ & $\begin{array}{l}+ \\
+\end{array}$ & - & - \\
\hline
\end{tabular}

\section{Discussion}

We have seen that the general pattern of breeding results is not only consistent with gametophytic pollen control, but also has none of the features characteristic of sporophytic pollen control (the occasional reciprocal differences, and the exceptional third class in one common-allele cross observed during this study, do not appear to be best interpreted as evidence for sporophytic pollen control). Brewbaker (1957) has shown that there is an association between the number of nuclei in a pollen grain when it is shed, the site of inhibition of incompatible pollen, and whether the pollen incompatibility reaction is gametophytic or sporophytic. In general, incompatible trinucleate pollen grains are unable to germinate or are inhibited at the stigma, and are 
associated with sporophytic pollen control, while incompatible binucleate pollen grains form pollen tubes that are inhibited in the style, and are associated with gametophytic pollen control. $P$. lanceolata forms trinucleate pollen (Brewbaker, 1967), but the incompatible pollen tubes are inhibited in the style (Nur, personal communication). However, the second pollen mitosis is completed unusually late in $P$. lanceolata, only just before anthesis, and all four other Plantago species tested have binucleate pollen (Brewbaker, 1967). These other tested species are not closely related to $P$. lanceolata, and it would be desirable to study pollen grain cytology of other species in the same section of the genus.

It has been suggested (Pandey, 1960) that sporophytic pollen control is derived from gametophytic, and that trinucleate pollen is derived from binucleate. The sporophytic pollen control appears to result from precocious gene activity associated with premature division of the pollen generative nucleus. It is possible that trinucleate pollen evolved recently in $P$. lanceolata, without the evolution of the normally associated sporophytic pollen control and stigmatic inhibition of incompatible pollen grains. The intriguing possibility remains, however, that other populations of $P$. lanceolata, or of allied species, may possess a sporophytic system.

A second topic of interest lies in the almost ubiquitous presence of male sterility in this self-incompatible species. Are the male steriles superfluous with respect to outbreeding, or do they make an important contribution to outbreeding in this already outbred species? Can an alternative explanation be found for the presence of the male sterility?

Crosses between relatives, such as sibcrosses and backcrosses, are regulated differently by the presence of male sterility and by the incompatibility system, because of differences in the mode of inheritance in these two systems. For example, although the inheritance of male sterility is not fully understood, it is known that male-sterile plants may leave up to 99 per cent. malesterile offspring (Correns, 1908). Crosses among the male-sterile portion of such a progeny would be prevented, although a proportion of such crosses would have been allowable under the incompatibility system. Similarly, sibcrossing among a wholly hermaphrodite progeny would be limited by the incompatibility system. Thus the two systems might reinforce each other.

An answer to the question of whether the male steriles make an important contribution to outbreeding in this species requires more data than are at present available. For example, it would be useful to know to what extent pollinations among closely related plants occur in nature. A better understanding of the inheritance of the male sterility would also be desirable. Despite the need for more data, however, it might prove instructive to set up a series of models to determine to what extent male sterility contributes to outbreeding in a self-incompatible species, under a variety of assumptions.

Acknowledgments. - Part of this work was carried out in the Oxford Botany Department, and is contained in a D.Phil. thesis submitted to the University of Oxford. The rest of the work was carried out in the Biology Department of Dalhousie University. I acknowledge the financial support of the Department of Scientific and Industrial Research, and the National Research Council of Canada. I thank Dr L. K. Crowe for supervising the first part of this work, and Professor C. D. Darlington, F.R.S., in whose department this study was initiated. I thank Mrs Lydia Ross and Miss Linda Carnell for technical assistance, Dr Bruce Weir of Massey University for statistical help, and Dr Uzi Nur of the University of Rochester for allowing me to cite his unpublished observations. 


\section{REFERENCES}

BAKER, H. G. 1963. Evolutionary mechanisms in pollination biology. Science, 139, 877-883. BATEMAN, A. J. 1954. Self-incompatibility systems in Angiosperms. II. Iberis amara. Heredity, 8, 305-332.

BReWBaker, J. L. 1957. Pollen cytology and self-incompatibility systems in plants. $\mathcal{F}$. Hered., 48, 271-277.

BREWBAKER, J. L. 1967. The distribution and phylogenetic significance of binucleate and trinucleate pollen grains in the Angiosperms. Amer. F. Bot., 54, 1069-1083.

CORRENS, C. 1908. Die Rolle der männlichen Keimzellen bei der Geschlechtsbestimmung der gynodioecischen Pflanzen. Ber. deut. Bot. Ges., 26a, 686-701.

DENWARD, T. 1963. The function of the incompatibility alleles in red clover (Trifolium pratense L.). II. Results of crosses in inbred families. Hereditas, 49, 203-236.

EAST, E. M., AND MANGELSDORF, A. J. 1925. A new interpretation of the hereditary behavior of self-sterile plants. Proc. Nat. Acad. Sci., 11, 166-171.

EAST, E. M., AND PARK, J. B. 1917. Studies on self-sterility. I. The behavior of self-sterile plants. Genetics, 2, 505-609.

LEWIS, D. 1954. Comparative incompatibility in the Angiosperms and fungi. Adv. Genet., $6,235-285$.

LEWONTIN, R. C., AND PROUT, T. 1956. Estimation of the number of different classes in a population. Biometrics, 12, 211-223.

MATHER, к. 1940. Outbreeding and separation of the sexes. Nature, 145, 484-486.

PANDEY, K. K. 1960. Evolution of gametophytic and sporophytic systems of self-incompatibility in Angiosperms. Evolution, 14, 98-115.

PANDEY, K. K. 1970. New self-incompatibility alleles produced through inbreeding. Nature, 227, 689-690.

Ross, M. D. 1969. Digenic inheritance of male sterility in Plantago lanceolata. Can. F. Genet. Cytol., 11, 739-744.

Note added in proof.-I am indebted to Dr J. L. Brewbaker, University of Hawaii, for drawing my attention to the two-gene gametophytic incompatibility system proposed by F. V. Owen for Beta vulgaris (1942, J. Agr. Res., 64, 679 698). Beta, together with several grasses, is like Plantago in having trinucleate pollen and gametophytic incompatibility. 